\title{
Isolation and Partial Characterization of a Human Alveolar Macrophage-derived Neutrophil-activating Factor
}

\author{
James E. Pennington, Thomas H. Rossing, Lisa W. Boerth, and Tak H. Lee
}

Department of Medicine, Harvard Medical School, and Brigham and Women's Hospital, Boston, Massachusetts 02115

\begin{abstract}
Human alveolar macrophages (AM) were obtained from eight normal volunteers using fiberoptic bronchoscopic lavage to explore potential interrelationships among leukocytes in pulmonary defense against infection. AM placed in monolayer tissue cultures released material into culture supernatants with the capacity to enhance the bactericidal capacity of human neutrophils. Neutrophils preexposed to supernatants killed Pseudomonas aeruginosa from 70 to $90 \%$ more efficiently than control cells $(P<0.02)$. AM culture supernatants contained this material by $4 \mathrm{~h}$ of incubation, and in vitro stimulation of AM cultures with heat-killed $\boldsymbol{P}$. aeruginosa further increased its production.

Gel filtration of AM culture supernatants with a G-50 Sephadex column allowed isolation of a 6,000-D neutrophilactivating factor (NAF) that was resistant to heat $\left(56^{\circ} \mathrm{C}, 30\right.$ $\mathrm{min}$ ). The isoelectric point of NAF, as determined by chromatofocusing, was 7.6. Enzyme digestion of NAF specimens, prepared sequentially by gel filtration and chromatofocusing, demonstrated 50-70\% loss of activity after incubations with trypsin, chymotrypsin, and neuraminidase. NAF was only minimally chemotactic and eluted from Sephadex G-50 with particles of a different molecular size than those of AMderived chemotactic factors (i.e., $\sim 10,000 \mathrm{D}$ and $<500 \mathrm{D}$ ). Preincubation of neutrophils with NAF resulted in greater release of superoxide anion upon their subsequent stimulation by either bacterial phagocytosis or by phorbol myristate acetate, as compared with control neutrophils stimulated in a like manner. These studies indicate that human AM secrete a heatstable, low molecular weight basic protein, with the capacity to enhance oxidative microbicidal activity of neutrophils.
\end{abstract}

\section{Introduction}

The human alveolar macrophage (AM) ${ }^{1}$ is a potent secretory cell. In recent years, it has become evident that certain of these secretory activities may be critical to intrapulmonary defenses against infection (1-4). We have recently observed that supernatants obtained from short-term cultures of normal

Received for publication 28 November 1983 and in revised form 14 December 1984.

1. Abbreviations used in this paper: AM, alveolar macrophages; cfu, colony-forming units; f-met-leu-phe, formyl-methionyl-leucyl-phenylalanine; GBSS, Gey's balanced salt solution; HIFBS, heat-inactivated fetal bovine serum; IL-1, interleukin-1; $\mathrm{LTB}_{4}$, leukotriene $\mathrm{B}_{\mathbf{4}}$; NAF, neutrophil-activating factor; NANA, $N$-acetylneuraminic acid; PMA, phorbol myristate acetate; SOD, superoxide dismutase.

J. Clin. Invest.

(c) The American Society for Clinical Investigation, Inc.

$0021-9738 / 85 / 04 / 1230 / 08 \quad \$ 1.00$

Volume 75, April 1985, 1230-1237 human AM contain material that, upon exposure to neutrophils, enhances bactericidal activity of neutrophils (5). Neutrophils incubated with these supernatants demonstrated an increased respiratory burst during subsequent phagocytic challenge, an effect that was not related to increased phagocytic rates among the supernatant-exposed neutrophils. The addition of cycloheximide to AM tissue cultures eliminated most of the neutrophil-activating material in culture supernatants, suggesting that this material was synthesized and secreted by macrophages. It was not clear from these initial observations, however, whether AM culture supernatants contained one or several active principles. Nor was it clear whether these studies had detected a previously unknown substance, or whether they were simply describing new functional properties for previously identified AM secretory products $(2-4,6)$. The present study was undertaken to address these issues.

\section{Methods}

Bronchoalveolar lavage. Fiberoptic bronchoscopy was performed on eight healthy human volunteers (six male, two female) after informed consent was obtained. Volunteers were 25-36 yr of age, and half were smokers. The nose and upper airways were anesthetized with $4 \%$ lidocaine and a bronchoscope (model BF B2; Olympus Corporation of America, New Hyde Park, NY) was passed transnasally. The bronchoscope was wedged in a subsegmental bronchus of the right middle lobe or lingula and $200-250 \mathrm{ml}$ of sterile isotonic saline was instilled in 50-ml aliquots and aspirated by suction apparatus (1).

Preparation of AM tissue cultures and culture supernatants. Bronchoalveolar lavage fluid specimens were filtered through coarse gauze to remove mucus, then centrifuged at $500 \mathrm{~g}$ for $9 \min$ at $4^{\circ} \mathrm{C}$ to sediment cells. Supernatants were removed and cells resuspended and washed by gentle agitation in modified Hanks' balanced salt solution (HBSS) $\left(\mathrm{Ca}^{++}\right.$- and $\mathrm{Mg}^{++}$-free; Grand Island Biological Co., Grand Island, NY). Cells were counted by hemocytometer, and differential counts were made using Wright-Giemsa stained smears. In addition, wet mounts were prepared with dilute neutral red stain to differentiate macrophages from lymphocytes (7). Cell viability was assessed by trypan blue dye exclusion ( $>95 \%$ viable). Respiratory cell preparations were brought to a final concentration of $2 \times 10^{6} \mathrm{AM} / \mathrm{ml}$ in Medium 199 (M199; Grand Island Biological Co.) plus 10\% heat-inactivated (2 $h$ at $56^{\circ} \mathrm{C}$ ) fetal bovine serum (HIFBS) (Grand Island Biological Co.) plus $2 \%$ penicillin-streptomycin (Grand Island Biological Co.).

$2-\mathrm{ml}$ aliquots of cell suspension were placed into $15 \times 30 \mathrm{~mm}-$ flat-bottom plastic tissue culture dishes (Falcon Labware, Becton, Dickinson \& Co., Oxnard, CA), and cultures were incubated at $37^{\circ} \mathrm{C}$ in a moist atmosphere of $5 \% \mathrm{CO}_{2}$ for $2 \mathrm{~h}$ so that monolayers of $\mathrm{AM}$ could adhere to culture plates. Nonadherent cells were then washed from plates with HBSS and cell cultures were refed with $2 \mathrm{ml}$ serumfree M199 plus $2 \%$ penicillin-streptomycin. Selected cell cultures were examined by inverted microscopy for each experiment and found to consist of $98-99 \%$ neutral red positive mononuclear cells. Cell-free tissue culture dishes containing equal volumes of M199 plus penicillinstreptomycin were also prepared during each experiment to provide control M199 (see below). Tissue cultures and cell-free plates were then incubated $\left(37^{\circ} \mathrm{C}, 5 \% \mathrm{CO}_{2}\right) 4,24$, or $72 \mathrm{~h}$. In selected experiments, AM $\left(2 \times 10^{6} / \mathrm{ml}\right)$ were placed into $13 \times 100 \mathrm{~mm}$-round-bottom plastic 
tubes (Falcon Labware) and incubated in suspension using a tilting rack. In addition, selected AM cultures were exposed to heat-killed Pseudomonas aeruginosa (see below) at $1 \times 10^{7}$ colony-forming units $(\mathrm{cfu}) / \mathrm{ml}$ concentration, or latex particles $(1.099 \mu \mathrm{m})$ (Dow Chemical U.S.A., Health \& Consumer Products Div., Indianapolis, IN) suspended at $2 \%$ concentration, during $4-$ or 24 -h incubations. After incubation, AM culture supernatants and fluids from cell-free plates were removed by Pasteur pipette, centrifuged at $500 \mathrm{~g}$ for $8 \mathrm{~min}$ to remove cellular debris, passed through micropore filters $(0.45 \mu \mathrm{m})$, and frozen to $-70^{\circ} \mathrm{C}$.

Preparation and preincubation of neutrophils. Venous blood from healthy volunteers was collected into syringes containing heparin and sedimented with dextran (Macrodex 6\%; Pharmacia Fine Chemicals, Div. of Pharmacia Inc., Piscataway, NJ); neutrophils were then collected by processing the leukocyte-rich fractions over density cushions (FicollPaque; Pharmacia Fine Chemicals) (8), and residual erythrocytes were lysed with $0.2 \%$ saline exposures. Tonicity was rapidly restored using $1.6 \%$ saline. Resultant cell preparations contained $99 \%$ polymorphonuclear leukocytes with $\sim 95 \%$ viability (trypan blue dye exclusion). Wright-Giemsa stains revealed that $>95 \%$ of these cells were neutrophils. Neutrophils were suspended to a concentration of $1 \times 10^{7}$ cells $/ \mathrm{ml}$ in either M199 from the cell-free plates plus 10\% HIFBS, native AM culture supernatants plus $10 \%$ HIFBS, or partially purified AM supernatants (by gel filtration and chromatofocusing, see below). Each of these mixtures was incubated for $15 \mathrm{~min}$ at $37^{\circ} \mathrm{C}$ in a shaking water bath, after which neutrophils were sedimented at $500 \mathrm{~g}$, supernatants removed, and cells resuspended to $1 \times 10^{7}$ neutrophils $/ \mathrm{ml}$ in HBSS with $\mathrm{Ca}^{++}$and $\mathrm{Mg}^{++}$. Cell viabilities of these final suspensions were routinely $98-99 \%$ (trypan blue dye).

Bactericidal assay. A serum-resistant strain of $P$. aeruginosa (Pseudomonas, strain 220) was prepared as described previously (9), and suspended in isotonic saline to a final concentration of $1 \times 10^{8} \mathrm{cfu} /$ ml. Mixtures $\left(0.3 \mathrm{ml}\right.$ vol) containing $1 \times 10^{7}$ bacteria, $1 \times 10^{6}$ preincubated neutrophils (see above), and $7 \%$ fresh autologous human serum were prepared in triplicate in plastic tubes $(12 \times 75 \mathrm{~mm}$; Falcon Labware) and incubated at $37^{\circ} \mathrm{C}$ in a shaking water bath. After 0 and $120 \mathrm{~min}$, samples were serially diluted in distilled $\mathrm{H}_{2} \mathrm{O}$ and cultured using the pour-plate technique.

Positive-pressure ultrafiltration and gel filtration of AM culture supernatants. AM supernatant specimens were fractionated using a positive-pressure ultrafiltration apparatus (Amicon Corp., Scientific Sys. Div., Danvers, MA). For fractionation, 2-ml samples were diluted with M199 to $10 \mathrm{ml}$, then filtered using a filter (model UM-10; Amicon Corp.) and concentrated to original volumes. Filtrates were collected and also concentrated to original volumes using another filter (model UM-05; Amicon Corp.). Resulting fractions, containing material of $>10,000 \mathrm{D}$ (model UM-10), or between 500 and 10,000 D (model UM-05), were then assayed for neutrophil-activating capacity.

1-ml samples of supernatant fluids from selected AM cultures were gel-filtered using $1.0 \times 60-\mathrm{cm}$ columns containing Sephadex G-50 (Pharmacia Fine Chemicals). The columns were operated at $4^{\circ} \mathrm{C}$ using

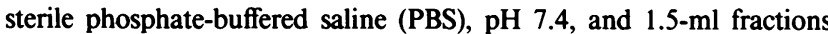
were collected. Alternate eluant fractions were then assayed for their capacity to increase bactericidal activity of neutrophils. The columns were calibrated with blue dextran $\left(2 \times 10^{6} \mathrm{D}\right)$, soybean trypsin inhibitor $(20,100 \mathrm{D})$, cytochrome $c(12,400 \mathrm{D})$, insulin $(5,200 \mathrm{D})$, glucagon $(3,400 \mathrm{D})$, and tryptophan $(260 \mathrm{D})$. All markers were obtained from Sigma Chemical Co., St. Louis, MO.

Chromatofocusing. Eluant fractions obtained from gel filtration and found to contain peak neutrophil-activating activity were pooled and dialyzed overnight at $4^{\circ} \mathrm{C}$ against $0.025 \mathrm{M}$ Tris- $\mathrm{CH}_{3} \mathrm{COOH}$ buffer, $\mathrm{pH} 8.3$, and $15-\mathrm{ml}$ samples were applied to a $1.8 \times 30-\mathrm{cm}$ column of polybuffer exchanger 94 (Pharmacia Fine Chemicals), which had been previously equilibrated with the same buffer. A solution of polybuffer 96 (30\%; Pharmacia Fine Chemicals) and polybuffer $74(70 \%)$ $\mathrm{CH}_{3} \mathrm{COOH}$, pH 5.0 (Pharmacia Fine Chemicals), was used for elution using a flow rate of $35 \mathrm{ml} / \mathrm{h}\left(4^{\circ} \mathrm{C}\right)$. A linear $\mathrm{pH}$ gradient of $800 \mathrm{ml}$ from $\mathrm{pH} 8.0$ to $\mathrm{pH} 5.0$ was generated and $5.0-\mathrm{ml}$ fractions were collected. Every fifth fraction was dialyzed overnight at $4^{\circ} \mathrm{C}$ against

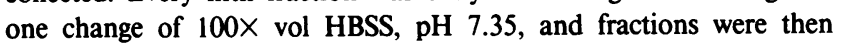
assayed undiluted for neutrophil-activating capacity. The column was regenerated with $1 \mathrm{M} \mathrm{NaCl}$ and reequilibrated with the $0.025 \mathrm{M}$ Tris$\mathrm{CH}_{3} \mathrm{COOH}$ buffer before each experiment. The fractions collected during $1 \mathrm{M} \mathrm{NaCl}$ washes were also collected, pooled, dialyzed as above, and assayed for neutrophil-activating capacity.

Enzyme digestion. Insoluble trypsin, chymotrypsin, and neuraminidase were obtained from Sigma Chemical Co. Enzyme digestion experiments were performed on neutrophil-activating factor (NAF) that had been partially purified by gel filtration, followed by chromatofocusing, and finally dialyzed against HBSS (as above). Enzyme concentrations used for digestions were $3.2 \%(6.4 \mathrm{U} / \mathrm{ml})$ trypsin, $1.6 \%$ $(7.2 \mathrm{U} / \mathrm{ml})$ chymotrypsin, and $1.6 \%(0.64 \mathrm{U} / \mathrm{ml})$ neuraminidase. For experiments, enzymes were suspended in $1.0-\mathrm{ml}$ aliquots of NAF and mixtures were incubated on a tilter at $37^{\circ} \mathrm{C}$ for 45 or $180 \mathrm{~min}$. After incubations, insoluble enzyme was separated from NAF by centrifugation $(3,000 \mathrm{~g})$, and supernatants were then assayed for neutrophilactivating capacity. Control experiments included HBSS incubated with each of the enzymes, and NAF and HBSS preincubated for 180 min without enzymes.

To document that the neuraminidase used for these digestions was active at physiologic $\mathrm{pH}$, we carried out enzyme digestions of $\mathrm{N}$-acetyl neuraminlactose (from bovine colostrum; Sigma Chemical Co.) at pH 5.5 and at physiologic $\mathrm{pH}$ (7.35), both in HBSS. Reaction mixtures were incubated for $30 \mathrm{~min}$ at $37^{\circ} \mathrm{C}$, and micromoles of $\mathrm{N}$-acetylneuraminic acid (NANA) in the samples was assayed by the thiobarbituric acid method of Warren (10). Synthetic NANA (Aldrich Chemical Co., Inc., Milwaukee, WI) was used to establish the standard curve. In comparing the micromoles of NANA released per milliliter at each $\mathrm{pH}$, there was a $38 \%$ reduction in activity at the higher $\mathrm{pH}$, indicating that our enzyme as used in this study did retain considerable activity. Neuraminidase used for assays was lot 33F-9560 (Sigma Chemical Co.) and contained minimal protease activity $(0.007 \mathrm{U}$ protease/1 $\mathrm{U}$ neuraminidase).

Chemotactic assay. Chemotactic assays were carried out on alternate eluant fractions from the gel filtration preparations using modified Boyden chambers (Ahlco Manufacturing Co., Inc., Southington, CT). For these assays, human neutrophils were collected and prepared as described above, except that final suspensions were made in Gey's balanced salt solution (GBSS) plus $0.4 \%$ bovine serum albumin (BSA; Sigma Chemical Co.), at a concentration of $2.5 \times 10^{6} \mathrm{cells} / \mathrm{ml}$. For assays, $400 \mu \mathrm{l}$ of neutrophil suspension was placed in the upper compartments of the chambers, and the eluant fraction (or control substances) loaded into the lower compartment. Negative controls included GBSS plus $0.4 \%$ BSA, and also PBS with and without $0.4 \%$ BSA. No significant differences in chemotactic activity were detected among the three negative control suspensions used. For positive controls, a $10^{-8}-\mathrm{M}$ suspension of formyl-methionyl-leucyl-phenylalanine (f-met-leu-phe) was used (11). Upper and lower compartments were separated by $3-\mu \mathrm{m}$ pore cellulose nitrate filters (Membranfilter, Sartorius, Gottingen, Federal Republic of Germany), and chambers were incubated for $30 \mathrm{~min}$ at $37^{\circ} \mathrm{C}$ in a moist atmosphere of $5 \% \mathrm{CO}_{2}$. Filters were then removed, fixed in methanol, and prepared for microscopy, as previously described (11). Triplicate filters were obtained for each specimen (or control). The distance in micrometers the leading pair of neutrophils had migrated into each filter was determined using a microscope micrometer (12), and readings were repeated five times per filter. Chemotaxis for each specimen was expressed as the mean distance $(\mu \mathrm{m})$ of migration for all readings.

Leukotriene $B_{4}\left(L T B_{4}\right)$ assay. AM from four different volunteers were prepared in culture exactly as described above. Supernatants were then harvested after 24-h incubations, 1.5 vol of absolute methanol was added, and the samples stored at $-70^{\circ} \mathrm{C}$, under argon, until used for measurement of $\mathrm{LTB}_{4}$. Before the $\mathrm{LTB}_{4}$ assay, the specimens were evaporated to dryness under vacuum. The residues were resuspended in $500 \mu \mathrm{l}$ of $10 \mathrm{mM}$ Tris- $\mathrm{HCl}$ buffer, $\mathrm{pH} 7.4$, containing $0.15 \mathrm{M} \mathrm{NaCl}$ and $0.1 \%$ gelatin, and a $100-\mu 1$ sample of each was assayed in a 
radioimmunoassay for $\operatorname{LTB}_{4}(13,14)$. The standard curve for the inhibition of binding of ${ }^{3} \mathrm{H}-\mathrm{LTB}_{4}$ to anti-LTB $\mathrm{LT}_{4}$ antibody was obtained over the ranges of $0.01-10 \mathrm{ng} \mathrm{LTB}_{4}$; the $\mathrm{ID}_{50}$ for $\mathrm{LTB}_{4}$ was $0.18 \mathrm{ng}$ (15). The $\mathrm{LTB}_{4}$ used was made by total chemical synthesis (16) (kindly given by Professor E. J. Corey, Harvard University, Cambridge, MA). The purity of the compound was confirmed by its elution as a homogeneous peak after reverse phase high pressure liquid chromatography, and its concentration was determined from the maximum UV absorbance using the maximal molar extinction coefficient of 51,000 $\mathrm{cm}^{-1} \mathbf{M}^{-1}$. To assess the recovery of immunoreactive $\mathrm{LTB}_{4}$ from $\mathrm{AM}$ supernatants, defined quantities of $\mathrm{LTB}_{4}$ as determined by UV absorbance were added to AM supernatants. The supernatants were processed as described above and recoveries of immunoreactive LTB $_{4}$ were consistently $>90 \%$ for $0.03-10 \mathrm{ng} \mathrm{LTB}$. $_{4}$.

Superoxide anion $\left(\mathrm{O}_{2}^{-}\right)$assay. The production of $\mathrm{O}_{2}^{-}$by neutrophils preincubated with partially purified (gel filtration) NAF was measured by the capacity of $\mathrm{O}_{2}^{-}$to reduce ferricytochrome $c$ to ferrocytochrome $c$ (17). Control neutrophil preparations were preincubated with PBS only. After preincubation for $15 \mathrm{~min}$, neutrophils were washed and resuspended $\left(5 \times 10^{6}\right.$ cells in HBSS with $\mathrm{Ca}^{++}$and $\left.\mathrm{Mg}^{++}\right)$with ferricytochrome $c$, type VI $(1.24 \mathrm{mg} / \mathrm{ml}$ ) (Sigma Chemical Co.), either with or without superoxide dismutase (SOD, $100 \mu \mathrm{g} / \mathrm{ml}$; Sigma Chemical Co.). These reagents were prepared immediately before usage. Phorbol myristate acetate (PMA; Sigma Chemical Co.) or viable $P$. aeruginosa were used to trigger the respiratory burst. All preparations were made in triplicate. Neutrophil reaction-mixtures were incubated for $\mathbf{4 5} \mathrm{min}$ at $37^{\circ} \mathrm{C}$ in a shaking water bath, after which cells were sedimented at $300 \mathrm{~g}$, and supernatants removed for assay. Identically prepared reactionmixtures were also assayed without incubation, to determine background activity. Supernatants were diluted 1:4 in HBSS with $\mathrm{Ca}^{++}$and $\mathrm{Mg}^{++}$ and assayed for reduction of ferricytochrome $c$ by spectrophotometric analysis (Cary 219, recording spectrophotometer; Cary Instruments, Monrovia, CA). Nanomoles of cytochrome $c$ reduced were calculated from the maximal increase in absorbance measured using an absorption coefficient of $21.1 \mathrm{mM}^{-1} \mathrm{~cm}^{-1}$ (18). Superoxide-dependent cytochrome $c$ reduced was calculated by subtraction of the value for cytochrome $c$ reduced measured in the reaction-mixtures containing SOD from the value measured in the reaction-mixtures without SOD. Results are expressed as nanomoles of cytochrome $c$ reduced per $5 \times 10^{6}$ neutrophils.

Immunological methods and chemical reagents. Polyclonal goat antisera to human $\mathrm{C}_{5}$ was obtained from Atlantic Antibodies (Scarborough, ME). Goat anti-human $\mathrm{C}_{3}$ was kindly donated by Dr. Harvey R. Colten, Children's Hospital Medical Center, Boston, MA (19). Rabbit anti-human albumin was obtained from Cappel Laboratories, Cochranville, PA. Agar-gel double diffusion assays were carried out by the method of Ouchterlony (20). The functional neutralizing capacity of the anti- $\mathrm{C}_{5}$ antisera used was verified by the demonstration that anti- $C_{5}$ antisera could eliminate neutrophil chemotactic activity in zymosan-activated fresh human serum (distances migrated [ $\mu \mathrm{m}]: 114 \pm 8$, activated serum; $52 \pm 7$, activated serum reacted $2 \mathrm{~h}$ with antisera; $46 \pm 8$, GBSS control). 1-ml aliquots of AM culture supernatant specimens were then reacted with $0.1 \mathrm{ml}$ antisera to $C_{3}, C_{5}$, or albumin for $2 \mathrm{~h}$ at room temperature. Antisera to human albumin was included in these experiments to determine whether antisera-induced neutralization was complement specific. M199 alone was concomitantly incubated with these antisera. Untreated AM supernatant and M199 were also incubated for $2 \mathrm{~h}$ at room temperature. All reaction mixtures, plus the untreated materials, were then used for the conventional 15-min preexposure of neutrophils, followed by bactericidal assay.

$N$-f-met-leu-phe was obtained in powdered form from Bachem Fine Chemicals (Torrance, CA), dissolved in dimethyl sulfoxide, and diluted to working concentrations in GBSS. The final concentration of dimethyl sulfoxide was $<1 \%$. Zymosan was obtained from Difco Laboratories Inc. (Detroit, MI), and was used to activate fresh human serum, as previously described (2).

Statistical analysis. Experimental data were analyzed using the paired two-tailed $t$ test. A $P$ value of $<0.05$ was considered significant.

\section{Results}

Initial studies using the eight newly generated human AM culture specimens confirmed our previous observation (5). Neutrophils preexposed to supernatants from 24-h AM cultures reduced numbers of viable Pseudomonas by $3.01 \pm 0.33\left(\log _{10}\right)$ during 120 -min incubations, while a mean decrease $\left(\log _{10}\right)$ of $2.13 \pm 0.27$ was noted for neutrophils preexposed to medium only $(P<0.02)$. There was no significant difference between the AM supernatants obtained from smokers and nonsmokers in their capacity to activate neutrophils. In additional experiments, serial twofold dilutions of AM culture ( $24 \mathrm{~h}$ ) supernatants were made in M199 before neutrophil exposure. Considerable neutrophil-activating capacity remained in preparations up to dilutions of 1:8 $(P<0.05)$ (Fig. 1).

Influence of $A M$ cell culture conditions on secretion of neutrophil-activating material. The optimal incubation time for recovery of neutrophil-activating material was $4 \mathrm{~h}$, and incubation of AM for longer periods did not increase the amount of detectable neutrophil-activating material (Fig. 2). The maximal recovery of AM-derived material was achieved when the cell cultures were exposed to $10^{7} \mathrm{cfu}$ heat-killed $P$. aeruginosa (Fig. 2). Challenge of monolayers with inert latex particles did not enhance recovery of AM-derived material, however. Finally, it was apparent that surface contact of AM was a requirement for stimulation of AM-derived material, since AM incubated in suspension failed to produce this substance (Fig. 2).

Exclusion of complement components and $\mathrm{LTB}_{4}$ to account for neutrophil-activating material in AM culture supernatants. Experiments were carried out to explore the possible association of neutrophil-activating material in AM supernatants with $\mathrm{LTB}_{\mathbf{4}}$, an arachidonic acid metabolite known to be produced by human $\mathrm{AM}(6,14,21)$, and also known to stimulate neutrophils (22). Previous experience has indicated that calcium ionophore stimulation of AM is necessary for optimal $\mathrm{LTB}_{4}$ production (6). However, it was our intent to duplicate the cell culture conditions used herein for producing NAF. Thus, all sets of AM cultures $\left(2 \times 10^{6}\right.$ cells $\left./ \mathrm{ml}\right)$ were incubated for $24 \mathrm{~h}$ without calcium ionophore stimulation. The concentra-

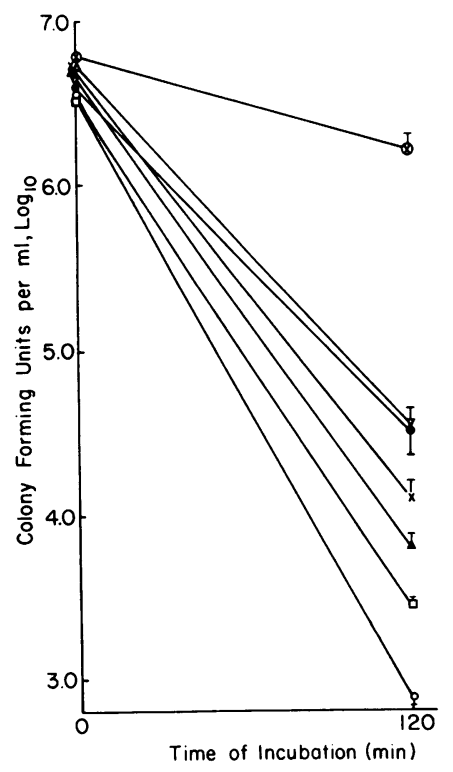

Figure 1. Bactericidal activity during 120-min incubations of neutrophils preexposed to $\mathrm{AM}$ supernatants, undiluted $(O)$, or diluted 1:2(口), 1:8(ه), 1:16 $(\times)$, or $1: 32(\bullet)$ with $M 199$, or preexposed to M199 alone $(\nabla)$ Cell-free killing activity $(\otimes)$ is also shown. Values are mean ( \pm SEM) for four separate experiments. Values different than M199 alone are the following: supernatants diluted 1:8 $(P<0.05), 1: 2(P<0.02)$, and undiluted $(P<0.02)$. 


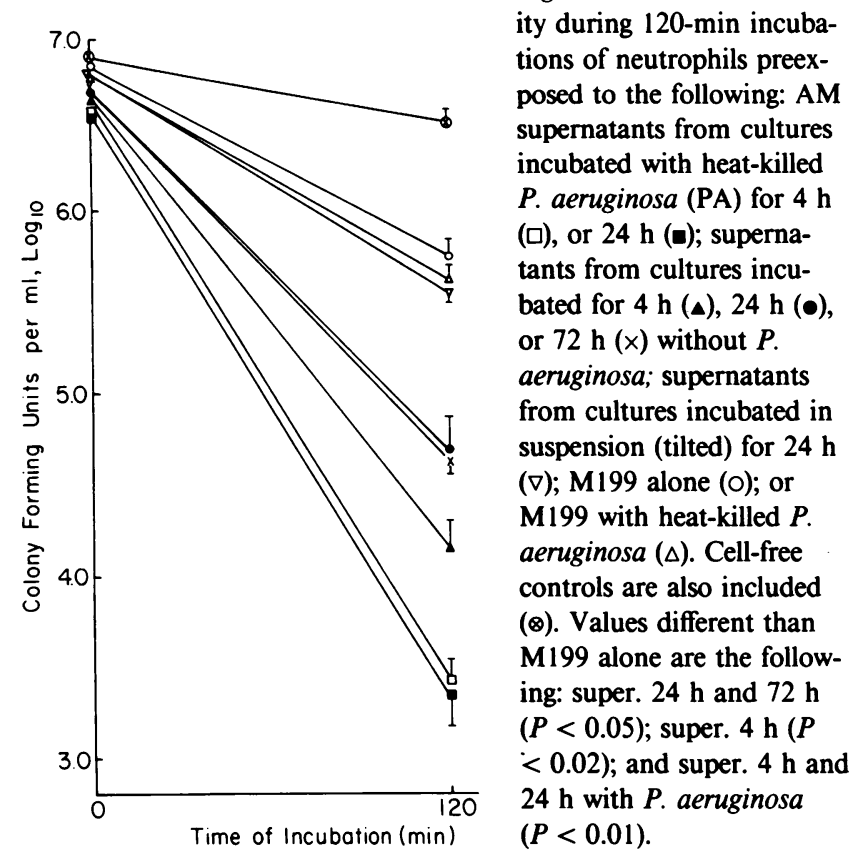

tions of $\mathrm{LTB}_{4}$ detected in AM cell culture supernatants (containing potent neutrophil-activating capacity) from four different volunteers were $0.38,0.31,0.81$, and $0.33 \mathrm{ng} / \mathrm{ml}$. These concentrations are far less than those previously associated with stimulation of neutrophil aggregation and respiratory burst (22).

Since human AM are also known to secrete certain complement proteins (4), and since $C_{3}$ and $C_{5}$ may stimulate a variety of neutrophil activities $(23,24)$, experiments were carried out to explore the possible association of neutrophilactivating material in AM supernatants with $C_{3}$ or $C_{5}$. Antisera to $C_{3}, C_{5}$, and albumin were reacted against fresh human sera, and also against five separate AM supernatant specimens in agar-gel double diffusion assays. Single precipitation bands were detected for each antiserum when reacted against serum, but no bands were visible in reactions against the AM supernatants (antisera were used undiluted, and also in 1:10, 1:100, 1:1,000 dilutions). In addition, an attempt was made to neutralize neutrophil-activating capacity in the AM supernatants by immunologic means. No reduction of neutrophil-activating capacity was evident for any of the antisera-exposed specimens. Nor did antisera-exposed M199 demonstrate alterations in neutrophil-activating properties as compared with M199 alone.

Positive-pressure ultrafiltration and gel filtration. To determine the molecular weight of neutrophil-activating materials contained in AM culture supernatants, samples were first screened using a positive-pressure ultrafiltration apparatus. Ultrafiltration was carried out on two separate AM supernatant specimens. Exposure of neutrophils to UM-05 filter fractions resulted in 60 (specimen 1) and 74 (specimen 2) \% fewer viable Pseudomonas after 120-min incubations, as compared with buffer controls. The UM-10 filter fractions contained no neutrophil-activating material, suggesting that the molecule(s) was between 500 and 10,000 D.

Based upon these screening studies, a Sephadex G-50 column was selected for more precise identification of molecular weight(s). Molecular sieve chromatography was carried out on five separate AM supernatant specimens (four 24-h cultures, one 4-h culture), and the results obtained were virtually identical. A representative experiment is shown in Fig. 3. The major peak of neutrophil-activating material eluted with particles of $\sim 6,000 \mathrm{D}$; this material is referred to as "neutrophil-activating factor." A smaller peak of neutrophil-activating material was also detected, eluting with particles of $\sim 12,000 \mathrm{D}$.

Since previous studies have described low molecular weight AM-derived chemotactic factors $(2,3)$ and since certain chemotactic factors are known to stimulate nonlocomotive neutrophil activities $(23,25)$, we considered the possibility that NAF and AM-derived chemotactic factors were related. The eluant fractions collected from three separate gel filtration experiments were thus assayed for chemotactic activity. Two peaks of chemotactic activity were consistently detected, and one such experiment is depicted in Fig. 4. One peak was detected in fractions corresponding to the elution position for material of $\sim 10,000-12,000 \mathrm{D}$. A separate low molecular weight peak of activity was detected in eluant fractions below the fractionation range of the G-50 column (i.e., <1,500 D). Little chemotactic activity was detected in the eluant fractions corresponding to the elution position for the 6,000-D NAF. It thus appeared that NAF was separate from AM-derived chemotactic factors. It did appear, however, that the high molecular

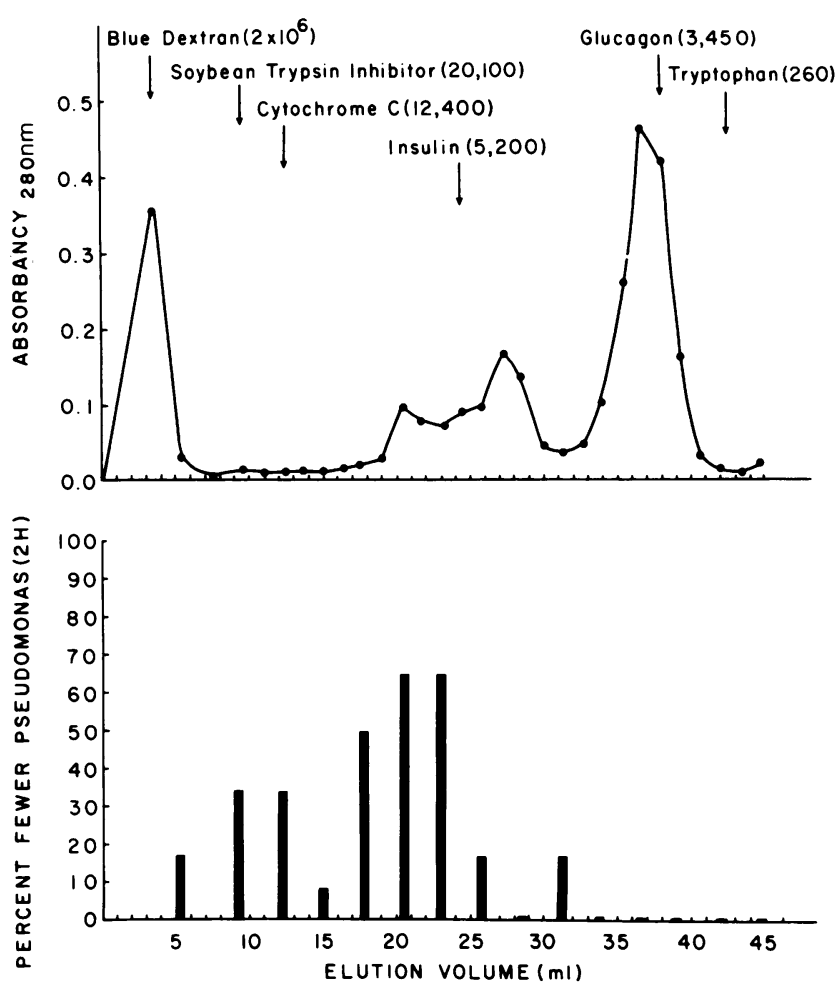

Figure 3. Chromatogram of gel filtration of AM culture supernatant through Sephadex G-50 column. Supernatant was eluted with PBS (pH 7.4). Elution positions of known molecular weight markers are indicated by arrows, and protein content in elution fractions is estimated by absorbancy $(280 \mathrm{~nm})$, as shown in top panel. In lower panel, the neutrophil-activating capacity of individual eluant fractions is shown. These activities are expressed as the percentage fewer viable Pseudomonas in reaction mixtures after 120-min incubations with neutrophils preexposed to the eluant fractions, as compared with neutrophils preexposed to buffer only. 


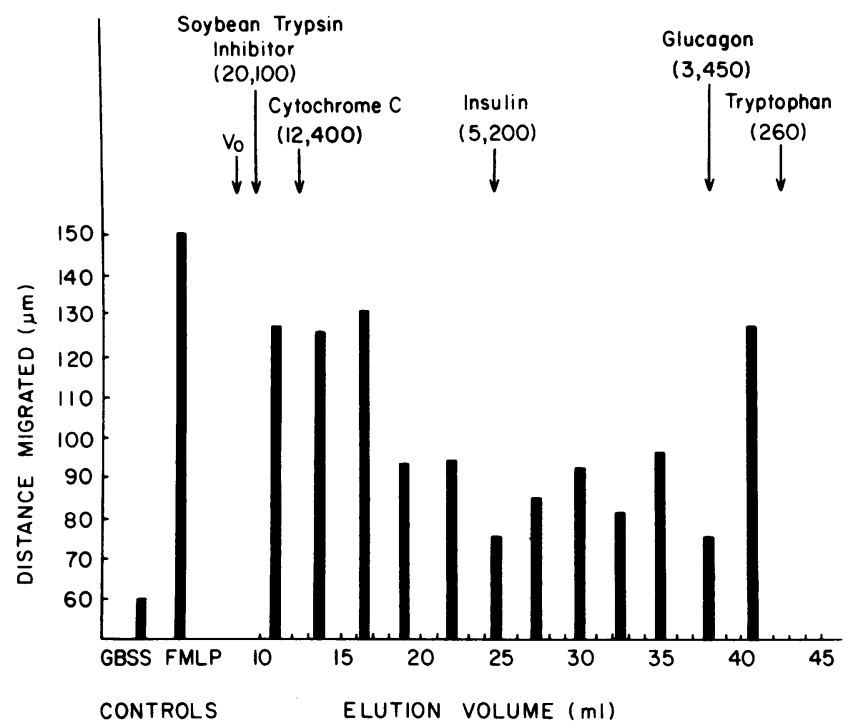

Figure 4. Neutrophil chemotactic activity (expressed as distance migrated, $\mu \mathrm{m}$ ) in individual eluant fractions obtained from gel filtration of AM supernatant. Positions of known molecular weight markers indicated by arrows. Controls for chemotaxis assay were GBSS plus $0.4 \% \mathrm{BSA}$ and $10^{-8} \mathrm{M}$ f-met-leu-phe (FMLP). Vo, void volume.

weight chemotactic factor might possess weak neutrophilactivating capacity (Figs. 3 and 4).

Chromatofocusing. Three separate samples containing NAF, each of which had been partially purified by gel filtration, were subjected to chromatofocusing, which separates proteins according to their isoelectric points. Virtually identical results were obtained, and a representative chromatogram is shown in Fig. 5. A single peak of neutrophil-activating material was consistently observed between $\mathrm{pH} 7.4$ and 7.8 for all specimens. There was no NAF detectable in pooled fractions obtained from columns during regenerations with $1 \mathrm{M} \mathrm{NaCl}$, indicating that all the neutrophil-activating material had been eluted

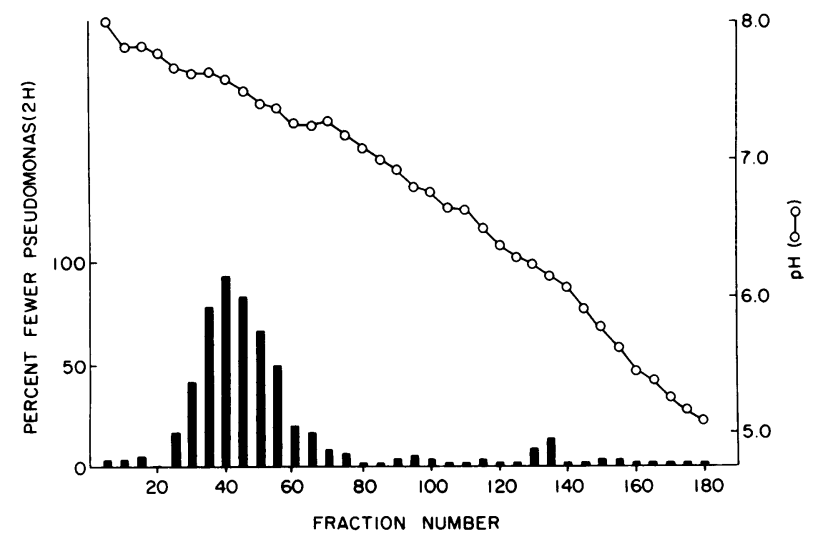

Figure 5. Chromatofocusing of NAF. The samples subjected to this procedure were eluant fractions obtained from Sephadex G-50 gel filtration of AM culture supernatants and documented to contain NAF. Samples were dialyzed against $0.025 \mathrm{M}$ Tris acetic acid buffer, $\mathrm{pH} 8.3$, before being applied to the column. Neutrophil-activating capacity is expressed as percent fewer viable Pseudomonas in reaction mixtures after 120-min incubations with neutrophils preexposed to the eluant fractions, as compared with neutrophils preexposed to buffer only. during chromatofocusing. Column fractions containing NAF (fraction 40), or not containing NAF (fractions 20 and 80), were also assayed for neutrophil chemotactic activity. Experiments were repeated twice, and mean values for distances migrated were the following $(\mu \mathrm{m})$ : fraction $20,82 \pm 6$; fraction $40,75 \pm 6$; fraction $80,78 \pm 4$; GBSS control, $89 \pm 3$; f-met-leuphe control, $148 \pm 2$. Thus, NAF appeared to be devoid of chemotactic activity after this second separation procedure.

Enzyme digestion. NAF specimens prepared sequentially by Sephadex G-50 gel filtration and chromatofocusing were treated with trypsin, chymotrypsin, or neuraminidase in each of two experiments, yielding very similar results. A representative experiment is shown in Fig. 6. All three enzymes produced between 50 to $70 \%$ reduction in NAF activity. The efficacy of digestion appeared to be time-dependent, particularly for chymotrypsin and neuraminidase.

Effect of heat. Two separate samples containing NAF, each of which had been partially purified by gel filtration, were heated $\left(56^{\circ} \mathrm{C}\right)$ for $30 \mathrm{~min}$. Heated and (paired) unheated specimens were then assayed for neutrophil-activating capacity, and results expressed as percent fewer viable Pseudomonas in reaction mixtures after 120 -min incubations with neutrophils preexposed to the NAF-containing samples, as compared with neutrophils exposed to buffer only. These values were 72 and $62 \%$ for the unheated samples, and 69 and $60 \%$ for the respective heated samples, indicating that NAF is relatively heat-stable.

Influence of NAF on superoxide production by resting and stimulated neutrophils. The influence of NAF on $\mathrm{O}_{2}^{-}$production by resting and stimulated neutrophils was evaluated. Eluant fractions obtained by Sephadex G-50 chromatography, and previously shown to contain NAF (see Fig. 3), were used for these experiments. Preexposure of neutrophils for $15 \mathrm{~min}$ to eluant fractions containing NAF did not result in increased production of $\mathrm{O}_{2}^{-}$during the preexposure, or over subsequent 45-min periods, as compared with neutrophils preexposed to buffer alone (Fig. 7). However, neutrophils first exposed to NAF and then stimulated by phagocytosis of viable $P$. aeru-

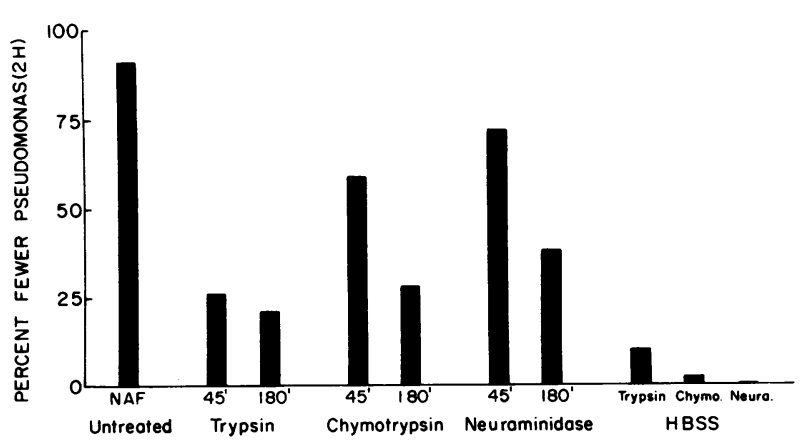

Figure 6. Enzyme digestion of NAF exposed to $3.2 \%$ trypsin, $1.6 \%$ chymotrypsin, or $1.6 \%$ neuraminidase, for $45\left(45^{\prime}\right)$ or $180\left(180^{\prime}\right) \mathrm{min}$ $\left(37^{\circ} \mathrm{C}\right)$. The specimens used for digestion were sequentially and partially purified by gel filtration and chromatofocusing. Controls included NAF without enzymes (untreated), but also incubated for $180 \mathrm{~min}$ at $37^{\circ} \mathrm{C}$; HBSS without enzymes, but incubated $180 \mathrm{~min}$; and HBSS incubated with enzymes for $180 \mathrm{~min}$. Neutrophil-activating capacity is expressed as percent fewer viable Pseudomonas in reaction mixtures after 120 -min incubations with neutrophils preexposed to enzyme-treated or -untreated NAF (or enzyme-treated HBSS), as compared with neutrophils preexposed to buffer alone. 

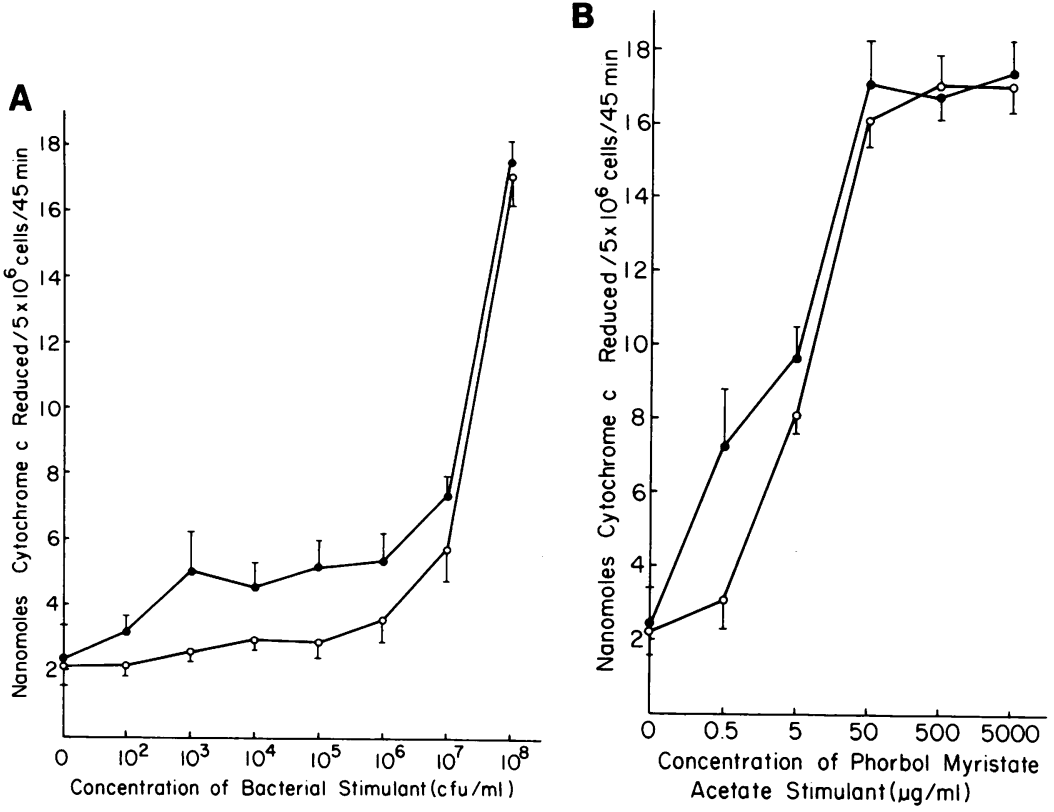

Figure 7. Production of $\mathrm{O}_{2}^{-}$(expressed as nanomoles of cytochrome $c$ reduced) by neutrophils preexposed for 15 min to PBS (0) or NAF containing eluant fractions $(\bullet)$, and then stimulated with incremental concentrations of viable $P$. aeruginosa $(A)$, or phorbol myristate acetate $(B)$. Values are mean $( \pm$ SEM) for three separate experiments. Values for NAF-exposed neutrophils are different than control neutrophils with $10^{3}$ and $10^{5} \mathrm{cfu}$ Pseudomonas $(P<0.05)(A)$, and with $0.5 \mu \mathrm{g} / \mathrm{ml}$ PMA $(P<0.02)(B)$. ginosa (Fig. $7 \mathrm{~A}$ ) or exposure to PMA (Fig. $7 \mathrm{~B}$ ), demonstrated enhanced $\mathrm{O}_{2}^{-}$production as compared with cells preexposed to buffer only. Enhancement was only evident with submaximal stimulation. For bacterial exposure, submaximal stimulation occurred over a broad dose-response range, but with PMA a rapid escalation to peak stimulation was noted.

\section{Discussion}

It is increasingly apparent that intrapulmonary mechanisms of defense against infection are complex in nature and, in some cases, unique to the lung $(1,26,27)$. The notion that AM singularly defend against bacterial pneumonia by virtue of their phagocytic activity (28) is not substantiated by recent observations $(2,3,29)$. Rather, it now appears that AMmediated immune modulation $(30,31)$ and chemoattraction $(2,3)$ of nonmacrophage inflammatory cell populations are nonphagocytic activities of great importance to defense of the lung. Clinical (32) and experimental $(29,33)$ observations have, in fact, confirmed that one of the critical determinants of outcome from bacterial pneumonia is the degree of neutrophil accumulation in airways and lung parenchyma. It thus appears that recently described AM-derived chemotactic factors $(2,3)$ have potential clinical importance. In this study, we have isolated from human AM culture supernatants an additional factor with the potential for amplification of local pulmonary defense against bacterial infections. NAF is $\sim 6,000$ $\mathrm{D}$, has an isoelectric point of 7.6, and appears to be stable under treatment with heat $\left(56^{\circ} \mathrm{C}\right)$ for $30 \mathrm{~min}$. In addition, enzyme digestion studies suggest that NAF is a protein.

Incubation conditions of AM influenced their secretion of NAF. It was apparent that cell surface stimulation was necessary for the secretion of NAF. Thus, nonadherent AM in the lung may not produce this material. However, since an adherent population of AM does exist in vivo (1), it is reasonable to postulate that in vivo surface stimulation may result in the secretion of NAF, even in noninfected lungs. In this instance, NAF may be important in the surveillance activities of the lung defense apparatus. The most potent stimulus to NAF secretion in these experiments occurred during AM exposure to bacterial cells, clearly suggesting a role for this substance in augmenting local defenses during pneumonia.

We have addressed the possibility that NAF is one of the previously described AM secretory products that affects neutrophils, such as the high molecular weight $(\sim 10,000 \mathrm{D})(2)$ and the low molecular weight $(\sim 500 \mathrm{D})(2,3)$ chemotactic factor, $5 S, 12 R$-dihydroxy-6,14-cis-8,10-trans-eicosateraenoic acid $\left(\mathrm{LTB}_{4}\right)$, a 5-lipoxygenase pathway metabolite of arachidonic acid $(6,14,21)$, or complement fragments (4). The isolation of a single peak of potent neutrophil-activating material by gel filtration and chromatofocusing suggested that NAF was not the net effect of several neutrophil-stimulating substances. In addition, NAF did not resemble $\mathrm{LTB}_{4}$ biochemically, nor could significant amounts of $\mathrm{LTB}_{4}$ be detected in AM culture supernatants cultured under conditions producing NAF. Furthermore, we excluded the possibility that NAF and previously identified AM-derived chemotactic factors were the same by carrying out concomitant bactericidal and chemotactic assays on eluant fractions. Only weak stimulation of neutrophilbactericidal activity was detected in fractions containing high molecular weight chemotactic factor. These observations were particularly interesting in light of past studies documenting stimulation of neutrophil-bactericidal activity by a variety of chemotactic factors $(23,25)$.

The recent observations that human AM synthesize certain complement components (4) raised the possibility that NAF may be related to AM-derived complement proteins with the capacity to activate neutrophils (e.g., $\left.\mathrm{C5}_{\mathrm{a}}, \mathrm{C} 3_{\mathrm{b}}\right)(23,24)$. Although past studies have been unable to detect hemolytically active $\mathrm{C}_{3}$ or $\mathrm{C}_{5}$ in normal human AM culture supernatants (4), $C_{3}$ has been detected in culture supernatants from activated human AM (4). In addition, we could not exclude the possibility that biologically active cleavage products of $C_{3}$ or $C_{5}$ were present in the AM supernatants. Accordingly, immunological neutralization of NAF with polyclonal anti- $C_{3}$ and anti- $C_{5}$ antibodies was attempted. Neither antiserum resulted in inhibition of NAF activity in AM supernatant, suggesting that biologically active fragments of $C_{3}$ or $C_{5}$ proteins did not 
account for the neutrophil-activating capacity in AM culture supernatants. Finally, even though recent studies suggest that activated AM from patients with sarcoidosis produce increased quantities of interleukin-1 (IL-1) (34), and there is evidence that IL-1 can affect neutrophils (35), the possibility that NAF is related to IL-1 is remote. Only small amounts of IL-1 are secreted by healthy human AM (36). Furthermore, human IL1 is $\sim 15,000 \mathrm{D}$, and has isoelectric points that are lower than those of NAF (37).

Since an increase in neutrophil oxidative microbicidal activity may be one mechanism of action for NAF, experiments were carried out to examine the quantitative relationship of NAF to neutrophil respiratory burst. These studies demonstrated that NAF-mediated enhancement of $\mathrm{O}_{2}^{-}$production by neutrophils was a graded response, only observed when submaximal stimuli were used. NAF did not increase the total $\mathrm{O}_{2}^{-}$produced by a maximally stimulated neutrophil population. It was also of interest that NAF exposure alone did not directly stimulate a respiratory burst by neutrophils. This suggests that in the noninfected lung, it is unlikely that AM generation of NAF results in the production by neutrophils of oxygen radicals potentially toxic to lung tissues. While the mechanism by which NAF enhanced the neutrophil oxidase enzyme system responsible for $\mathrm{O}_{2}^{-}$generation was not apparent, it is noteworthy that other polypeptides have been implicated in a dose-dependent stimulation of neutrophil respiratory burst (23, 38). It is also possible that NAF influenced nonrespiratory mechanisms of neutrophil killing.

In summary, this study describes yet another facet of the already complex pulmonary host defense apparatus. Determination of the biologic significance of NAF will ultimately require an in vivo evaluation. However, this AM secretory product is clearly one with potential to directly enhance pulmonary host defenses against bacterial infection.

\section{Acknowledgments}

The authors are grateful to Dr. R. A. Lewis for providing the anti$\mathrm{LTB}_{4}$ antibody used in these studies. We also wish to thank Dr. Harvey R. Colten for his helpful advice, and Miss Sahira Ansari and Miss Lynn Sayers for preparing the manuscript.

This work was supported in part by U. S. Public Health Service research grant HL-21997. Dr. Lee is the recipient of a Saltwell Research Fellowship from the Royal College of Physicians, London, England.

\section{References}

1. Hunninghake, G. W., J. E. Gadek, O. Kawanami, V. J. Ferrans, and R. G. Crystal. 1979. Inflammatory and immune processes in the human lung in health and disease: evaluation by bronchoalveolar lavage. Am. J. Pathol. 97:149-206.

2. Merrill, W. W., G. P. Naegel, R. A. Matthay, and H. Y. Reynolds. 1980. Alveolar macrophage-derived chemotactic factor: kinetics of in vitro production and partial characterization. J. Clin. Invest. 65:268-276.

3. Hunninghake, G. W., J. E. Gadek, H. M. Fales, and R. G. Crystal. 1980. Human alveolar macrophage-derived chemotactic factor for neutrophils: stimuli and partial characterization. J. Clin. Invest. 66: 473-483.

4. Cole, F. S., W. J. Matthews, T. H. Rossing, D. J. Gash, N. A. Lichtenberg, and J. E. Pennington. 1983. Complement biosynthesis by human bronchoalveolar macrophages. Clin. Immunol. Immunopathol. 27:153-159.
5. Pennington, J. E., T. H. Rossing, and L. W. Boerth. 1983. The effect of human alveolar macrophages on the bactericidal capacity of neutrophils. J. Infect. Dis. 148:101-109.

6. Fels, A. O. S., N. A. Pawlowski, E. B. Cramer, T. K. C. King, Z. A. Cohn, and W. A. Scott. 1982. Human alveolar macrophages produce leukotriene $\mathrm{B}_{4}$. Proc. Natl. Acad. Sci. USA. 79:7866-7870.

7. Cohn, Z. A., and E. Weiner. 1963. The particle hydrolases of macrophages. II. Biochemical and morphological response to particulate ingestion. J. Exp. Med. 118:1009-1020.

8. Boyum, A. 1968. Isolation of mononuclear cells and granulocytes from human blood. Scand. J. Clin. Lab. Invest. Suppl. 21(Suppl. 97): 77-89.

9. Pennington, J. E., and J. J. Miler. 1979. Evaluation of a new polyvalent Pseudomonas vaccine in respiratory infections. Infect. Immun. 25:1029-1034.

10. Warren, L. 1959. The thiobarbituric acid assay of sialic acids. J. Biol. Chem. 234:1971-1975.

11. Pennington, J. E., and E. A. Harris. 1981. Influence of immunosuppression on alveolar macrophage chemotactic activities in guinea pigs. Am. Rev. Respir. Dis. 123:299-304.

12. Zigmond, S. H., and H. G. Hirsch. 1973. Leukocyte locomotion and chemotaxis, new methods for evaluation, and demonstration of a cell-derived chemotactic factor. J. Exp. Med. 137:387-410.

13. Lewis, R. A., J.-M. Mencia-Huerta, R. J. Soberman, D. Hoover, A. Marfat, E. J. Corey, and K. F. Austen. 1982. Radioimmunoassay for leukotriene $\mathrm{B}_{4}$. Proc. Natl. Acad. Sci. USA. 79:7904-7908.

14. Godard, P., M. Damon, F. B. Michel, E. J. Corey, K. F. Austen, and R. A. Lewis. 1983. Leukotriene $B_{4}$ production from human alveolar macrophages. Clin. Res. 31:548a.

15. Lee, T. H., J.-M. Mencia-Huerta, C. Shih, E. J. Corey, R. A. Lewis, and K. F. Austen. 1984. Characterization and biological properties of 5,12-dihydroxy derivatives of eicosapentaenoic acid, including leukotriene $\mathrm{B}_{\mathrm{S}}$ and the double lipoxygenase product. J. Biol. Chem. 259: 2383-2389.

16. Corey, E. J., A. Marfat, G. Goto, and F. Brion. 1980. Leukotriene $B_{4}$, total synthesis and assignment of stereochemistry. $J$. Am. Chem. Soc. 102:7984-7986.

17. Babior, B. M., R. S. Kipnes, and J. T. Curnutte. 1973. Biological defense mechanisms. The production by leukocytes of superoxide, a potential bactericidal agent. J. Clin. Invest. 52:741-744.

18. Weening, R. S., R. Wever, and D. Roos. 1975. The quantitative aspects of the production of superoxide radicals by phagocytizing human granulocytes. J. Clin. Med. 85:245-252.

19. Morris, K. M., G. Goldberger, H. R. Colten, D. P. Aden, and B. B. Knowles. 1982. Biosynthesis and processing of a human precursor complement protein, pro-C3 in a hepatoma-derived cell line. Science (Wash. DC). 215:399-400.

20. Ouchterlony, O. 1958. Diffusion-in-gel methods for immunological analysis. Prog. Allergy. 5:1-78.

21. Martin, T. R., L. C. Altman, R. K. Albert, and W. R. Henderson. 1984. Leukotriene $\mathrm{B}_{4}$ production by the human alveolar macrophage: a potential mechanism for amplifying inflammation in the lung. Am. Rev. Respir. Dis. 129:106-111.

22. Serhan, C. N., A. Radin, J. E. Smolen, H. Korchak, B. Samuelsson, and G. Weissman. 1982. Leukotriene $B_{4}$ is a complete secretagogue in human neutrophils: a kinetic analysis. Biochem. Biophys. Res. Commun. 107:1006-1012.

23. Van Epps, D. E., and M. L. Garcia. 1980. Enhancement of neutrophil function as a result of prior exposure to chemotactic factor. J. Clin. Invest. 66:167-175.

24. Frank, M. M. 1979. The complement system in host defense and inflammation. Rev. Infect. Dis. 1:483-501.

25. Issekutz, A. C., K.-Y. Lee, and W. D. Biggar. 1979. Enhancement of human neutrophil bactericidal activity by chemotactic factors. Infect. Immun. 24:295-301. 
26. Kaltreider, H. B. 1976. Expression of immune mechanisms in the lung. Am. Rev. Respir. Dis. 113:347-379.

27. Reynolds, H. Y. 1983. Normal and defective respiratory host defenses. In Respiratory Infections: Diagnosis and Management. J. E. Pennington, editor. Raven Press, New York. 1-23.

28. Goldstein, E., W. Lippert, and D. Warshauer. 1974. Pulmonary alveolar macrophage: defender against bacterial infection of the lung. J. Clin. Invest. 54:519-528.

29. Pennington, J. E., and M. G. Ehrie. 1978. Pathogenesis of Pseudomonas aeruginosa pneumonia during immunosuppression. $J$ Infect. Dis. 137:764-774.

30. Mason, R., J. Austyn, F. Brodsky, and S. Gordon. 1982. Monoclonal anti-macrophage antibodies: human pulmonary macrophages express HLA-DR (Ia-like) antigens in culture. Am. Rev. Respir. Dis. 125:586-593.

31. Toews, G. B., W. C. Vial, M. M. Dunn, P. Guzzetta, G. Nunez, P. Statsny, and M. F. Lipscomb. 1984. The accessory cell function of human alveolar macrophages in specific $\mathrm{T}$ cell proliferation. J. Immunol. 132:181-186.

32. Fanta, C. H., and J. E. Pennington. 1981. Fever and new lung infiltrates in the immunocompromised host. Clin. Chest Med. 2:1939.

33. Dale, D. C., H. Y. Reynolds, J. E. Pennington, R. J. Elin, T. W. Pitts, and R. G. Graw. 1975. Granulocyte transfusion therapy of experimental pseudomonas pneumonia. J. Clin. Invest. 54:664-671.

34. Hunninghake, G. W. 1984. Release of interleukin-1 by alveolar macrophages of patients with active pulmonary sarcoidosis. Am. Rev. Respir. Dis. 129:569-572.

35. Klempner, M. S., C. A. Dinarello, W. R. Henderson, and J. I. Gallin. 1979. Stimulation of neutrophil oxygen-dependent metabolism by human leukocytic pyrogen. J. Clin. Invest. 64:996-1002.

36. Wewers, M. D., S. I. Rennard, A. J. Hance, P. B. Bitterman, and R. G. Crystal. 1984. Normal human alveolar macrophages obtained by bronchoalveolar lavage have a limited capacity to release interleukin1. J. Clin. Invest. 74:2208-2218.

37. Dinarello, C. A. 1984. Interleukin-1. Rev. Infect. Dis. 6:51-95.

38. Simchowitz, L., and I. Spilberg. 1979. Generation of superoxide radicals by human peripheral neutrophils activated by chemotactic factor. Evidence for the role of calcium. J. Lab. Clin. Med. 93:503593. 